\title{
Precise Engineering of Nanoassembled Corilagin Small Molecule into Supramolecular Nanoparticles for the Treatment and Care against Cervical Carcinoma
}

\section{Research Article}

Keywords:

Posted Date: March 22nd, 2021

DOI: https://doi.org/10.21203/rs.3.rs-232702/v2

License: (1) This work is licensed under a Creative Commons Attribution 4.0 International License. Read Full License 


\section{Abstract}

The authors have requested that this preprint be withdrawn due to author disagreement.

\section{Full Text}

The authors have withdrawn this preprint from Research Square. 